\title{
Reproductive effects of sodium borates on male employees: birth rate assessment
}

\author{
M Donald Whorton, Jenifer L Haas, Lisa Trent, Otto Wong
}

\begin{abstract}
Objectives-The purpose of the study was to investigate potential reproductive effects of sodium borates on occupationally exposed male employees at a large mining and production facility in the Mojave Desert of California.

Methods-The standardised birth ratio (SBR) was used to assess fertility of the male employees. Live births were the measured end point, and the rate of female to male offspring was also assessed. Data were collected through a questionnaire after a series of on site introductory and explanatory meetings with the employees. Initial non-responders were followed up by telephone. Medical insurance records were assessed for those who declined to participate.

Results-The questionnaire was a good method of ascertainment for live births. There was no evidence of selection bias in the results. There was a highly significant excess of offspring fathered by the male employees. There was no evidence of a relation between exposure and this excess of offspring, nor were there any temporal differences during the period of observation ( $>30$ years). Also, there was an excess of the percentage of female offspring fathered by these male employees. This excess of female offspring was not significant. There was no evidence of an exposure relation to sodium borates with this excess of female offspring nor were there any temporal differences.

Conclusion-Under the conditions studied, there were no adverse reproductive effects of high borate doses as reported from oral ingestion studies in animals.
\end{abstract}

(Occup Environ Med 1994;51:761-767)

ENSR Health

Sciences, 1320 Harbor Bay Parkway, Suite 210, Alameda, California 94502, USA M D Whorton $\mathrm{J}$ L Haas

L Trent

Applied Health Sciences, 181 Second Avenue, Suite 628, PO Box 2078, San Mateo, California 94401, USA O Wang

Correspondence to:

Dr M Donald Whorton

1320 Harbor Bay Parkway,

1320 Harbor Bay Park California 94502, USA.

Accepted 22 June 1994

\section{Keywords: sodium borates, male fertility}

The purpose of this study was to investigate potential reproductive effects of sodium borates on male employees who worked in a sodium borate mining and production facility in the Mojave Desert of California. Several scientifically valid studies have assessed the reproductive effects of sodium borates in oral ingestion studies on male laboratory animals. Although there are no similarly controlled studies in humans, Tarasenko et al suggested adverse human reproductive effects among Russian workers exposed to high levels of boric acid dust. ${ }^{1}$
The adverse effects of sodium borates were first reported by Caujolle et al in 1962, who used a massive single dose in rats. Later studies by Weir and Fisher ${ }^{3}$ and Dixon et $a l^{45}$ showed that chronic doses $>1000$ ppm boron in the diet of male rats produced testicular atrophy. Lower doses did not produce such effects. These studies have been replicated in mice by other investigators (Fail et $a l^{67}$ ). In recent studies of boron on tissue deposition in rats, Treinen and $\mathrm{Chapin}^{8}$ and $\mathrm{Ku} e t$ al $^{9}$ found no accumulation (above plasma concentrations) of boron in the testes or any other soft tissues. Lee et al showed that boron was more concentrated in the testes than the blood of rats. The only human data, reported on Russian workers by Tarasenko et al, suggest an effect on testicular function including sterility, but the workplace dust exposures were reported to be four to eight times the $10 \mathrm{mg} / \mathrm{m}^{3}$ Russian permissible exposure limit ${ }^{11}$ listed by the ILO.

Participants in our study were all employees of the US Borax mine and production facility in the Mojave Desert near Boron, California, in the United States. This relatively isolated site had a large group (750) of employees with occupational exposure to sodium borate dust and desert soil with little other exposure. The borate exposure covered many years, as this group offered a relatively long average length of service (18 years). Observations based on current exposure measurements are thought to be conservative, as exposures were most likely to be significantly higher before the 1980s. Individual information and results obtained during this study have been kept confidential in agreement with participants before the start of this study. Only statistical data and averages have been reported.

At the start of the study, there were no data regarding the reproductive effects, if any, on the company's employees exposed to sodium borate. Although there were various methods available to evaluate this issue, we suggested that any investigation of these employees use the least invasive and simplest technique as the initial investigative procedure. Although semen samples can be collected for analyses as we have done in previous studies, we recommended the use of the standardised birth ratio (SBR) described by Wong et al. ${ }^{12}{ }^{13}$ This recommendation was accepted, and this is the report of our study. We recognised that other reproductive variables such as time to conception are sensitive indicators of reproductive effects. Concern about recall bias would make the reliability of this type of 
retrospective information questionable over a long period of time. Joffé et al had already shown that recall bias for time to conception may be less than we originally thought. ${ }^{14}$

\section{Methods}

We examined any adverse influence of occupational exposures to sodium borates on fertility by studying the reproductive performance in terms of live births among the wives of the workers. The summary index for assessing the risk of infertility is the standardised birth ratio (SBR). Specifically, the number of live births born to the wives of the workers after exposure to jobs of concern (deferred by nine months to accommodate the normal human gestation period) was compared with the number of births that would be expected if the study population had (after adjustment for maternal age, race, parity, and calendar time period) the same reproductive experience as a comparable non-exposed United States population.

The number of expected live natural children born to the wives was derived from national female fertility rates (birth probabilities) by parity, maternal age, race, and calendar year for successive birth cohorts that have been published since 1917 by the National Center for Health Statistics (Mosher and Pratt $\left.^{15}\right)$. No state or local rates were available. As such, the fertility of married male workers can be indirectly inferred from that of their respective wives.

This approach assumes that the male subjects of the study are the exclusive consorts of their wives. Single men are not included in the analysis, as reliable data on their fathering of offspring will not be available. Male reproductive performance in terms of live births has been little studied, and only limited national male fertility rates have been published.

Another method to assess reproductive effects is to examine the ratio of male to female offspring. In the United States, the number of males born/1000 live births is 512 $(51.2 \%)$ with the number of females being $488(48.8 \%)$. The male/female ratio is 1.05 ; whereas the female/male ratio is 0.95 . In this report, we have described our results in terms of the percentage of female births present in the total population. ${ }^{16}$

If a toxic agent alters the spermatogenesis production process, then the number of sperm cells carrying the sex chromosome material ( $y$ for males and $x$ for females) theoretically can be altered. For example, if the spermatocytes carrying the y chromosome are selectively decreased, one may see an increase in the percentage of female births as the reproductive effect. Potashnik et $a l^{17}$ showed that females comprised $80 \%$ of the offspring who were fathered by men who had recovered from severe testicular effects caused by exposures to dibromochloropropane.

In October 1990, we travelled to the facility and made multiple presentations to small groups of employees. At the end of the presentations, a two page questionnaire was dis- tributed to each employee with the following questions:

employee's name and identification number; employee's race;

employee's marital status;

complete marital history, including date of marriage(s), date of divorce(s), spouse's date of birth, and number of children from each marriage;

information on offspring, including date of births and whether the child is natural, adopted, or stepchild;

infertility history, including vasectomy, mumps, etc.

A researcher met the employees to review the questionnaires for consistency and completeness. Questionnaires were mailed to employees who were absent from the facility on the days of the visit and to all non-respondents. Follow up telephone calls were made to employees who did not return their questionnaires and to solicit missing or discrepant information.

The questionnaires were coded and entered into a database. Any questionable, missing, inconsistent, or invalid values detected through the data editing process were corrected. To assess the quality of the data entry, a $20 \%$ systematic random sample of records was recoded by a different research associate. The coding error rate was $<1 \%$; any errors detected were subsequently corrected in the data base.

The SBR is simply the ratio of the observed number of births to the expected. An SBR lower (higher) than 100 indicates a deficiency (excess) in live births compared with the United States general experience. A statistical test based on the Poisson distribution was used to detect any significant departure of this ratio from unity at alpha levels 0.05 and 0.01 (Bailer and Ederer ${ }^{18}$ ), and confidence intervals were also calculated.

We were concerned that the non-participants might have a different history in fathering children than the participants. As the nonparticipants did not complete the questionnaire, there seemed to be no ready method to evaluate this concern. Then, upon further exploration, we learned that the company had health insurance eligibility information contained within the personnel records on all employees. Simply, these records listed the employee, spouse, and dependent children, including their dates of birth or age.

These insurance eligibility records were less complete than the questionnaire data as they would only keep information on current spouses and dependents. We recognised that the SBRs would be somewhat lower than those we found in the questionnaires, but we were assessing the non-participants for selection bias. We also recognised that nonrespondents' confidentiality was important; thus, we elected only to use the basic demographic family data described above that were contained in the personnel files.

A staff member made a separate visit to the facility to validate and check the completeness of the data provided on the questionnaires. 
We selected a $10 \%$ random sample of the questionnaires and conducted an audit of their corresponding medical insurance eligibility records. We found that these sources were not as complete-for example, children who were no longer dependents were not listed on the employees' health insurancehowever, there were no additional children in these records not previously identified from the completed questionnaires.

During a site visit, we collected detailed work history information for all of the employees. Job titles, departments, and dates were coded and entered into a separate data base. Again, these data were subjected to edits and any errors detected were corrected.

$\mathrm{Hu}$ et al studied the exposures of workers at the facility from 1981 to $1988 .{ }^{19}$ They evaluated certain job titles in each department and obtained a mean exposure level for that job title. Also, they estimated exposures for job titles within a department for which they did not obtain data by taking a weighted mean of those job titles for which they had data. Thus, for each job title and each department, they reported a mean exposure value.

There were two generic types of exposure categories during the study period of $\mathrm{Hu}$ et al, constant and non-constant. The constant exposure category had no changes in operations during that period; whereas, the nonconstant exposure departments (fusing and shipping) had workplace changes that affected exposures from 1981-8. For the constant exposure departments, we used the values for each job title as provided by $\mathrm{Hu}$ et al. For the non-constant exposure departments, there were two different sets of values due to the workplace changes. For example, in the fusing department there is one set of exposure values for 1981-3 and a different set for 1984-8. All of these exposure values included the protection factor that arose from use of respirators if they were used by employees in a particular job category. Depending on when the employee worked in each job, we used the appropriate exposure value.

Table 1 Study population characteristics: male employees

\begin{tabular}{lcc}
\hline & Participants $(n=542)$ & Non-participants $(n=211)$ \\
\hline Race (n (\%)): & $504(93)$ & $201(95)$ \\
White & $38(7)$ & $10(5)$ \\
$\quad$ Non-white & $27(5)$ & $18(9)$ \\
Marital status (n (\%)): & $451(83)$ & $168(80)$ \\
$\quad$ Single & $64(12)$ & $17(7)$ \\
Married & $0(0)$ & $8(4)$ \\
Divorced, separated, or widowed & $43 \cdot 4$ & $42 \cdot 7$ \\
Unknown & $15 \cdot 8$ & $15 \cdot 3$ \\
Average age & $27 \cdot 1$ & $27 \cdot 0$ \\
Average length of employment (y) & 1946 & 1947 \\
Average age at hire & 1974 & 1975 \\
Average year of birth & & \\
Average year of hire & & \\
\hline
\end{tabular}

Table 2 Observed (Obs) and expected (Exp) births and standardised birth ratios $(S B R)$ : male employees

\begin{tabular}{llll}
\hline & $O b s$ & Exp & $S B R(95 \% C I)$ \\
\hline Participants & 529 & $466 \cdot 6$ & $113(103 \cdot 3-123 \cdot 4)^{\star \star}$ \\
Non-participants & 155 & $169 \cdot 2$ & $92(78 \cdot 3-107 \cdot 4)$ \\
All employees & 684 & $635 \cdot 8$ & $108(100 \cdot 2-116 \cdot 3)^{\star}$ \\
\hline
\end{tabular}

$\star \mathrm{P}<0.05 ;{ }^{\star \star} \mathrm{P}<0.01$.
For 1989, we used the same data as for 1988. There were no uniform exposure data before 1981; however, based on reports from the company personnel, exposures were higher, especially in some departments. We elected the conservative approach and used the same data as provided by $\mathrm{Hu}$ et al for exposures before 1981 for each individual. As respirators were not used in the two departments with non-constant exposures described above, $\mathrm{Hu}$ et al multiplied those exposures by 3.5 to account for lack of protection from respirators.

As these exposure data were the most objective available, we used them in our analyses. We developed an average exposure value for each employee with these data.

\section{Results}

DEMOGRAPHIC

There were 753 eligible male employees on 1 October 1990. Five hundred and forty two $(72 \%)$ participated by completing the questionnaire: 426 by completing the self administered questionnaire and 116 by participating in the telephone administered questionnaire. There were 211 (28\%) who declined to participate in this study.

Table 1 shows the demographic information on the participants and non-participants. There were no significant differences between the participants and non-participants for race, marital status, average age, length of employment, age at hire, year of birth, or year of hire.

The questionnaire contained three questions regarding personal medical history: vasectomy, inability to conceive a child after more than one year of trying, and ever sought help for fertility problems. Almost all of the participants answered these questions (97\%). Thirty six per cent of the participants had had vasectomies. This compares with a national average of $7 \% .{ }^{14}$ Nine per cent had reported the inability to conceive a child with more than one year of trying; whereas, $5 \%$ had sought help for fertility problems. These two results are lower than the national averages of $15 \%$ and $8 \%$ respectively (Whorton et al ${ }^{20}$ ).

\section{STANDARDISED BIRTH RATIOS}

There were 529 observed births fathered by the participants when only 466.6 were expected, thus resulting in a significant excess in the standardised birth ratio $(S B R=113, P$ $<0.01$ ).

The SBR for the non-participants for whom some offspring may not have been counted in the insurance records is 92 , with 155 observed and 169.2 expected in births. Table 2 shows that the overall SBR for both groups is 108 , which is significant $(P<0.05)$.

We obtained the average borate exposure value for each of the participants. We then developed five equal sized exposure categories and used these five categories to assess the effects of sodium borate exposure on fertility and sex ratio of the offspring: $<0.82,0.82$ to $1.77,1.78$ to $2.97,2.98$ to 5.04 , and $>5.05$ $\mathrm{mg} / \mathrm{m}^{3}$. The mean exposures for each category 
Table 3 Characteristics of study population for five mean exposure categories: male employees

\begin{tabular}{|c|c|c|c|c|c|}
\hline \multirow[b]{2}{*}{ Characteristics } & \multicolumn{5}{|c|}{ Exposure categories $\left(\mathrm{mg} / \mathrm{m}^{3}\right)$} \\
\hline & $\begin{array}{l}\text { Mean (range) } \\
0 \cdot 37(<0 \cdot 82) \\
(n=108)\end{array}$ & $\begin{array}{l}\text { Mean (range) } \\
1 \cdot 34(0 \cdot 82-1 \cdot 77) \\
(n=108)\end{array}$ & $\begin{array}{l}\text { Mean (range) } \\
2 \cdot 23(1 \cdot 78-2 \cdot 97) \\
(n=108)\end{array}$ & $\begin{array}{l}\text { Mean (range) } \\
3 \cdot 98(2 \cdot 98-5 \cdot 04) \\
(n=109)\end{array}$ & $\begin{array}{l}\text { Mean (range) } \\
8 \cdot 58(\geqslant 5 \cdot 05) \\
(n=109)\end{array}$ \\
\hline \multicolumn{6}{|l|}{ Race (\%): } \\
\hline White & 88 & 95 & 93 & 92 & 96 \\
\hline Non-white & 12 & 5 & 7 & 8 & 4 \\
\hline \multicolumn{6}{|l|}{ Marital status (\%): } \\
\hline Single & 5 & 2 & 5 & 6 & 7 \\
\hline Married & 85 & $8 \overline{3}$ & 82 & 86 & 80 \\
\hline Divorced, separated, or widowed & 10 & 15 & 13 & 8 & 13 \\
\hline Had vasectomy (\%) & 29 & 43 & 34 & 41 & 35 \\
\hline Tried to conceive $>1$ y (\%) & 12 & 7 & 13 & 4 & 9 \\
\hline Sought help for fertility (\%) & 8 & 3 & 7 & 5 & 4 \\
\hline Length of employment (y) & $14 \cdot 1$ & $17 \cdot 0$ & $16 \cdot 2$ & $17 \cdot 3$ & $14 \cdot 6$ \\
\hline Age at hire & $30 \cdot 4$ & $26 \cdot 8$ & $27 \cdot 2$ & $26 \cdot 0$ & $25 \cdot 2$ \\
\hline Year of birth & 1945 & 1946 & 1946 & 1946 & 1947 \\
\hline Year of hire & 1976 & 1973 & 1974 & 1973 & 1975 \\
\hline Average age & $45 \cdot 0$ & $44 \cdot 3$ & 43.9 & 43.8 & $40 \cdot 2$ \\
\hline
\end{tabular}

were $0 \cdot 37,1 \cdot 34,2 \cdot 23,3 \cdot 98$, and $8 \cdot 58 \mathrm{mg} / \mathrm{m}^{3}$ respectively.

Table 3 shows the demographic characteristics for the five exposure categories. As expected there were minor differences among the five groups in most characteristics, but none were significantly different.

Table 4 shows the SBRs for each of the exposure categories for the male respondents. The SBRs are significantly raised for both the lowest (151) and highest (125) exposure categories. The SBRs of the middle three categories are close to the expected values. There was no statistical trend in these data.

We then compared participants who had worked at high exposure jobs for more than two years consecutively with participants in all other job categories. There were 42 participants in these jobs. They had worked in the high exposure jobs for a mean (range) of 4.9 $(2 \cdot 1-20 \cdot 4)$ years. The mean (range) exposure was $23 \cdot 2(17 \cdot 6-44 \cdot 8) \mathrm{mg} / \mathrm{m}^{3}$.

These 42 participants were somewhat older (average age of $47 \cdot 6$ ) and had worked for the company for an average of 22.8 years. Forty eight per cent had had a vasectomy and $3 \%$ sought help for infertility. The observed number of births for this group of highly exposed men for their total work history was near the expected number $(S B R=102)$.

Table 4 Observed (Obs) and expected (Exp) births and standardised birth ratios (SBR) for five mean categories of exposure: male respondents

\begin{tabular}{llrrl}
\hline Category & $n$ & Obs & Exp & SBR $(95 \% C I)$ \\
\hline$<0 \cdot 82$ & 108 & 94 & $62 \cdot 1$ & $151(121 \cdot 8-185 \cdot 5)^{\star \star}$ \\
$0 \cdot 82-1 \cdot 77$ & 108 & 108 & $104 \cdot 2$ & $104(84 \cdot 6-126 \cdot 5)$ \\
$1 \cdot 78-2 \cdot 97$ & 108 & 93 & $94 \cdot 1$ & $99(79 \cdot 8-121 \cdot 6)$ \\
$2 \cdot 98-5 \cdot 04$ & 109 & 114 & $110 \cdot 2$ & $103(85 \cdot 4-123 \cdot 2)$ \\
$\geqslant 5 \cdot 05$ & 109 & 120 & $95 \cdot 9$ & $125(103 \cdot 6-149 \cdot 5)^{\star}$ \\
\hline
\end{tabular}

${ }^{\star} \mathrm{P}<0.05 ;{ }^{\star \star} \mathrm{P}<0.01$

Table 5 Observed (Obs) and expected (Exp) births and standardised birth ratios (SBR) of male participants with $\geqslant 2$ consecutive years of high exposure (only exposed time)

\begin{tabular}{llll}
\hline Time after beginning/end of high exposure & Obs & Exp & $S B R(95 \%$ CI $)$ \\
\hline 12 months/12 months & 26 & $21 \cdot 5$ & $121(79 \cdot 1-177 \cdot 4)$ \\
15 months/12 months & 24 & 20.0 & $120(76 \cdot 4-178 \cdot 6)$ \\
18 months/12 months & 22 & $19 \cdot 2$ & $115(71 \cdot 9-174 \cdot 2)$ \\
Total work history & 59 & $57 \cdot 6$ & $102(77 \cdot 9-131 \cdot 3)$ \\
\hline
\end{tabular}

We wanted to know if the SBR for these 42 highly exposed employees was influenced during the time the participants were actually working in the highly exposed jobs. We looked at the SBRs for three periods after the beginning of high exposure: 12,15 , and 18 months. We also followed the individuals for one year after the end of the high exposure period. The 12, 15, and 18 month periods were chosen to allow for 1,2 , and 3 complete spermatogenic cycles to occur in the male employees after beginning work in the high exposure job. The 12 months after was included to examine the effects of high exposure but not too long to allow for recovery of spermatogenesis if an adverse effect had occurred. A normal human spermatogenic cycle is about 90 days: $70-72$ days in the testis and 7-21 days in the epididymis.

Table 5 shows that in all of these periods, the observed births were in excess of expected. This seems to show that no adverse effects on fertility occurred during this period of high exposure. As stated above, the average calculated exposure during high exposure was $23 \cdot 2 \mathrm{mg} / \mathrm{m}^{3}$.

The plant had a long strike in 1973-4. There was a concern that the excess SBRs could be related to that strike. A non-significant raised SBR of 136 was found during the nine month period after the beginning of the strike and this continued for nine months after the end of the strike. As this SBR represents an excess of only 4.5 births, it does not account for the overall raised SBR for the male participants at the plant.

Finally, we examined the participants' SBRs by increments of five years from 1950 to 1990. Table 6 shows that there has been a consistent excess in the SBR in every five year period. There was no significant trend over time in either direction.

PERCENTAGE OF FEMALE OFFSPRING

Another measure of reproductive outcome is the ratio between the number of male offspring to female offspring. For every 1000 children born in the United States, 512 are boys; whereas, 488 are girls. Thus, the average percentage of female offspring is $48 \cdot 8$; the 
Table 6 Observed (Obs) standardised birth ratios (SBR) by 5 y groups: male participants

\begin{tabular}{lrl}
\hline Years & Obs & $S B R(95 \%$ CI $)$ \\
\hline $1950-1954$ & 5 & $226(73 \cdot 1-528 \cdot 0)$ \\
$1955-1959$ & 25 & $135(87 \cdot 1-199 \cdot 1)$ \\
$1960-1964$ & 44 & $101(73 \cdot 7-135 \cdot 2)$ \\
$1965-1969$ & 43 & $108(78 \cdot 8-144 \cdot 6)$ \\
$1970-1974$ & 58 & $112(85 \cdot 5-144 \cdot 1)$ \\
$1975-1979$ & 78 & $113(89 \cdot 7-140 \cdot 7)$ \\
$1980-1984$ & 152 & $128(108 \cdot 9-149 \cdot 4) \star \star$ \\
$1985-1990$ & 124 & $101(83 \cdot 7-120 \cdot 8)$ \\
All participants & 529 & $113(103 \cdot 3-123 \cdot 4)^{\star \star}$ \\
\hline$\star \star P<0 \cdot 01$ & &
\end{tabular}

Table 7 Female offspring (\%) for all participants and the five exposure categories

\begin{tabular}{ll}
\hline Category & Female offspring (\%) $(95 \%$ CI $)$ \\
\hline$<0 \cdot 82$ & $55 \cdot 3(45 \cdot 2-65 \cdot 4)$ \\
$0 \cdot 82-1 \cdot 77$ & $56 \cdot 5(47 \cdot 1-65 \cdot 9)$ \\
$1 \cdot 78-2 \cdot 97$ & $51 \cdot 6(41 \cdot 4-61 \cdot 8)$ \\
$2 \cdot 98-5 \cdot 04$ & $50 \cdot 9(41 \cdot 7-60 \cdot 1)$ \\
$\geqslant 5 \cdot 05$ & $49 \cdot 2(40 \cdot 2-58 \cdot 2)$ \\
Total & $52 \cdot 7(48 \cdot 4-57 \cdot 0)$ \\
\hline
\end{tabular}

Table 8 Female offspring (\%) by 5 y groups: male employees

\begin{tabular}{ll}
\hline Years & Female offspring (\%) $(95 \% \mathrm{CI})$ \\
\hline $1950-1954$ & $60 \cdot 0(17 \cdot 1-100 \cdot 0)$ \\
$1955-1959$ & $52 \cdot 0(32 \cdot 4-71 \cdot 6)$ \\
$1960-1964$ & $45 \cdot 5(30 \cdot 8-60 \cdot 2)$ \\
$1965-1969$ & $37 \cdot 2(22 \cdot 8-51 \cdot 7)$ \\
$1970-1974$ & $58 \cdot 6(45 \cdot 9-71 \cdot 3)$ \\
$1975-1979$ & $57 \cdot 7(46 \cdot 7-68 \cdot 7)$ \\
$1980-1984$ & $55 \cdot 9(48 \cdot 0-63 \cdot 8)$ \\
$1985-1990$ & $50 \cdot 8(42 \cdot 0-59 \cdot 6)$ \\
All participants & $52 \cdot 7(48 \cdot 4-57 \cdot 0)$ \\
\hline
\end{tabular}

corresponding percentage for male offspring is $51 \cdot 2$.

For the participants, there were 279 girls born when 228 were expected, an excess of 51 girls. For the boys, 250 were born when 239 were expected, an excess of 11 boys. Although there were more girls than boys, there was an excess of both. Therefore, the altered birth ratio in the participants is not due to a deficit of boys. For the non-participants, there were 80 girls born when 76 were expected and 75 boys with 79 expected.

As the excess in girls rather than boys becomes the question to examine, for the rest of this report we will use the terminology "percentage of female offspring".

Table 7 shows that $52 \cdot 7 \%$ of offspring of all the participants were female, almost significant. Table 7 also shows the percentage

Table 9 Distribution of children by sex by family size: male participants

\begin{tabular}{|c|c|c|c|c|c|c|c|c|c|}
\hline $\begin{array}{l}\text { Children/ } \\
\text { family (n) }\end{array}$ & $\begin{array}{l}\text { Children } \\
\text { (n) }\end{array}$ & $\begin{array}{l}\text { Families } \\
\text { (n) }\end{array}$ & \multicolumn{7}{|c|}{ Ratio boys/girls in family } \\
\hline 1 & 122 & 122 & $\begin{array}{l}0 / 1 \\
64\end{array}$ & $\begin{array}{l}1 / 0 \\
58\end{array}$ & & & & & \\
\hline 2 & 210 & 105 & $\begin{array}{l}0 / 2 \\
25\end{array}$ & ${ }^{1 / 1}$ & $\begin{array}{c}2 / 0 \\
16\end{array}$ & & & & \\
\hline 3 & 141 & 47 & $\begin{array}{l}0 / 3 \\
6\end{array}$ & 18 & $17^{2 / 1}$ & $\begin{array}{l}3 / 0 \\
6\end{array}$ & & & \\
\hline 4 & 40 & 10 & $\begin{array}{l}0 / 4 \\
1\end{array}$ & $\begin{array}{l}1 / 3 \\
4\end{array}$ & $\begin{array}{l}2 / 2 \\
2\end{array}$ & $\begin{array}{l}3 / 1 \\
1\end{array}$ & $\begin{array}{l}4 / 0 \\
2\end{array}$ & & \\
\hline 5 & 10 & 2 & $\begin{array}{l}0 / 5 \\
0\end{array}$ & $\begin{array}{l}1 / 4 \\
0\end{array}$ & $\begin{array}{l}2 / 3 \\
0\end{array}$ & $\begin{array}{l}3 / 2 \\
1\end{array}$ & $\begin{array}{l}4 / 1 \\
1\end{array}$ & $\begin{array}{l}5 / 0 \\
0\end{array}$ & \\
\hline 6 & 6 & 1 & $\begin{array}{l}0 / 6 \\
0\end{array}$ & $\begin{array}{l}1 / 5 \\
0\end{array}$ & $\begin{array}{l}2 / 4 \\
0\end{array}$ & $\begin{array}{l}3 / 3 \\
1\end{array}$ & $\begin{array}{l}4 / 2 \\
0\end{array}$ & $\begin{array}{l}5 / 1 \\
0\end{array}$ & $\begin{array}{l}6 / 0 \\
0\end{array}$ \\
\hline
\end{tabular}

female offspring by the five exposure categories. The two lowest exposures categories have the highest percentage of female offspring compared with the other three. There is no statistical trend among these five categories.

The female sex ratio for the 42 participants during the period of high exposure (more than two years) is $52.5 \%$ compared with $52.8 \%$ for the rest of the participants. There was no difference between the two groups.

Table 8 shows the percentage of female offspring by the five-year groups. Except for the decade of the $1960 \mathrm{~s}$, the percentage of female offspring was raised (50s, 70s, and $80 \mathrm{~s})$. The percentage of female offspring has also been raised since the time of the strike in 1974 .

When we collected the questionnaire data at the plant from the employees, we were told by several employees that mainly female offspring were fathered by the employees in the RESR area (pilot plant). When we examined the gender of the offspring of these employees, 12 of the 21 offspring $(57 \%)$ were females. This increase was not significant.

A suggested hypothesis for the increase in female offspring was that many male employees had girls but also wanted a boy so they kept siring children until a boy was born. This would mean that there should be many families with several girls and only one boy. Table 9 shows that there are essentially the same number of families with only one boy and the other girls (86) as there are families with one girl and the rest boys (83). Similarly, in families with three or more children, 29 have either all girls or all girls and one boy; whereas 27 families have either all boys or all boys and one girl. Thus, this hypothesis was disproved.

\section{ASSESSMENTS OF VALIDITY OF RESULTS}

In most epidemiological studies, all of the potential study subjects do not participate. Such was the case with this study. We looked at three different methods to determine if any obvious bias had occurred in our data collection procedures. Are the participants and non-participants similar? Are the self administered and telephone administered participants similar? How do the insurance eligibility record data compare with the questionnaire data?

The data indicate (table 1) that the nonparticipants were not demographically different from the participants. As the non-participant data were not as complete as the questionnaire data from the participants due to incomplete ascertainment, their fertility as measured by the SBR was relatively similar to the participants. Thus, we see no notable bias introduced by the non-participants.

Those who responded to the telephone administered questionnaire had not initially completed a self administered questionnaire. When we examined the demographic characteristics, SBRs, and percentage of female offspring for those who completed the self administered questionnaires compared with those who only completed one through 
telephone interview, there were essentially no differences between the two groups for length of employment, age at hire, year of birth, year of hire, age, vasectomy rate, percentage who tried to conceive for more than one year, and percentage who sought help for fertility problems.

The SBRs for the two groups were both in excess of the expected 100 . The self administered group had 426 observed births for a SBR of $112(P<0.05)$. The telephone administered group was smaller with 103 births for a SBR of 121, which approached significance. Similarly, there were only minor differences in the SBR by the different exposure assessments.

The percentage of female offspring was slightly higher for the self administered group (53.3) than the telephone administered group (50.5), but both were above the expected $48 \cdot 8 \%$. The female offspring by exposure category were not different between the two groups.

Thus, there seems to be little difference between those who answered the questionnaire through the self administered route compared with those who only responded to a telephone inquiry.

As previously described in the Methods section, we selected a $10 \%$ random sample of the participants and reviewed their insurance eligibility records. We then compared the questionnaire data to the insurance data for comparability of SBRs and percentage of female offspring. The questionnaire data had slightly higher SBRs (129 to 123) and a slightly lower percentage of female offspring $(51.9$ to $56 \cdot 5)$. None of these differences were significant.

We then compared the $10 \%$ sample of participants with the non-participants. The $10 \%$ sample of participants was younger and had been employed for fewer years than the nonparticipants; however, these differences were not significant. The $10 \%$ sample group had a higher SBR (123 $v 92)$ and a greater percentage of female offspring ( $56.5 v 51.6)$ than the non-participants. These differences were not significant.

\section{Discussion}

The purpose of this study was to assess if workplace exposures to sodium borates has caused an alteration to the male reproductive system as measured by fertility. We used the standardised birth ratio method to determine fertility. We also examined percentage of female offspring.

The study of the male workforce exposed to sodium borate showed a significant increase in the number of children sired by the men. This increase seems to be consistent over the time of the study (1950s to 1980 s). None of the analyses suggested anything but an excess of children compared with the national average.

None of the various methods we used to evaluate exposures and other temporal factors, seemed to be related to the exposures.
The highest SBR was seen in the lowest exposed group but the second highest SBR was in the highest exposed group. When we examined the men who worked for two or more years in the highest exposure category, their SBRs did not seem to be adversely affected by this exposure. This was true if one waited for three, six, or nine months after the beginning of exposure to start counting conceptions and ultimate births. This contrasted with dibromochloropropane, where the testicular effects were seen within three months and were clearly evident within two years (Whorton et $a l^{20}$ ). In the dibromochloropropane case, the workers themselves had recognised that the fertility abilities of the men diminished after they started working in the area with dibromochloropropane.

The excess of children in the present study is within a population that has a vasectomy rate nearly five times the national average. One would expect the expected birth rates to be lower in populations with higher vasectomy rates. Thus, the SBRs we report may be an underestimation of the true SBR if the vasectomy rates among the national population were the same as the local population.

The percentage of men who reported unsuccessful attempts with conception for more than one year is about half the national average. The percentage of men seeking medical attention for infertility is also less than the national reported averages. Thus, one must conclude that, in this population exposed to borate, infertility is not an issue.

The reverse ratio of girls to boys born to male employees is not significant, although in a few analyses, this difference becomes significant. The increase in girls is not due to a deficit in boys, but rather just a considerable increase in girls. For the participants, there were 11 more boys than expected compared with 51 more girls. This increase in the number of girls has been consistent for the decades of the $50 \mathrm{~s}, 70 \mathrm{~s}$, and $80 \mathrm{~s}$. Only during the 1960 s were boys born at a higher percentage than girls.

The increase in the percentage of female offspring seems to be inversely related to sodium borate exposure in the total population (table 7) as the lowest two exposure groups have the greatest percentage of female offspring. The percentage of female offspring sired by the 42 men during the highest exposure period was the same as the overall result from the entire participant population. The only human data on the ratio of girls to boys born among men who had recovered from the adverse affects of dibromochloropropane showed about $80 \%$ of the offspring to be girls (Potashnik et al $^{17}$ ). Also, an increase in girls born to certain types of fighter pilots and chemists has been reported (Amato ${ }^{21}$ ).

Based on the data in this study, we cannot determine why the male employees exposed to sodium borates have an increase in female offspring. Based on our assessments of bias, we do not believe that we selectively missed any group of live births. Thus, we believe that the data reported here are representative of 
the fertility as assessed by live births for this population of employees exposed to borate.

The questionnaire method used in this study was first used by Wong et al. ${ }^{12}$ It has been subsequently used extensively by Levine et $a l,{ }^{22}$ Wong et $a l,{ }^{13}$ and others. The power to find a positive result (either excess or deficit) in our study was very good. As shown in our data, we found significant findings at $P<0.01$ when the excess of births was only $13 \%$.

The fertility rates for women used in this questionnaire method are not adjusted for marriage. As married women have more children than do unmarried women but the fertility rates combine both married and unmarried women, a cohort of married women is expected to have a greater birth ratio than the total population that comprises both married and unmarried women. To compensate for this effect, we conducted internal comparisons with the exposure classification values developed by $\mathrm{Hu}$ et al. ${ }^{19}$ We found no evidence of an effect based on borate exposure and birth outcomes.

Although this questionnaire method does not evaluate the function of the male gonads directly, it does provide information about the ultimate end point: ability to conceive and have the conceptus born alive. Any direct gonadal study in this population would be hampered by the high vasectomy rate.

Like most workplace studies, a weakness of this study was the lack of complete historical exposure data. For the years 1981 to 1988 , we relied upon excellent assumptions on exposure data collected by $\mathrm{Hu}$ et al during their respiratory morbidity study. ${ }^{19}$ We also used their assumptions in categorising exposures before the dates of their study (1981) but recognise that this underestimates these earlier exposures. All of the exposure classifications by jobs and departments were completed before our analyses. Also, we did not participate in any of the exposure categorisations.

Based on the average exposures of those 42 men in the jobs with highest exposure for two or more years, we calculated the average exposure to sodium borate dust to have been $203 \mathrm{mg} /$ day. This assumes seven hours a day of actual exposure at the average concentration of $23.2 \mathrm{mg} / \mathrm{m} .^{3}$ The estimated eight hour respiratory volume for light work is $10 \mathrm{~m}^{3}$, then the amount for a seven hour day should be $8.75 \mathrm{~m}^{3}$. With the average or usual boron content of the sodium borates being $14 \%$, then the daily dose of boron (assuming 100\% absorption) is $28.4 \mathrm{mg}$. No adverse effects were found at that dose.

This study has importance to the estimated one million workers exposed to sodium borates in the United States and Europe.
Most, if not all of these workers have lower exposures than the study group. Based on the findings of this study, one would not anticipate any adverse reproductive effects in the less exposed population. This research was performed by ENSR Health Sciences under
contract with US Borax Corporation, Valencia, California. We thank the following for their support, review, and work on this study: Maureen Lennon, Philip Strong, Dwight Culver, Peter Shen, Laura Akin, Colleen Needels, Susan Yasuhara, Carol McKevitt, Stacy Griser, and Philip Lerner.

1 Tarasenko NY, Kasparov AA, Strongina OM. Effect of boric acid on the generative function in males. Gigiena Truda $i$ Professionalnye Zabolevaniya 1972;11:13-6.

2 Caujolle F, Familiades C, Souard J, Gout R Pharmacodynamie. Limite de tolerance du Rat a l'acide borique. Compte-Rendus de l'Acadamie des Sciences 1962; 254:3449-51.

3 Weir RJ, Fisher RS. Toxicologic studies on borax and boric acid. Toxicol Appl Pharmacol 1972;23:351-64.

4 Dixon RL, Lee IP, Sherins RJ. Methods to assess reproductive effects of environmental chemicals: studies of cadmium and boron administered orally. Environ Health Perspect 1976;13:59-67.

5 Dixon RL, Sherins RJ, Lee IP. Assessment of environmental factors affecting male fertility. Environ Health Perspect 1979;30:53-68.

6 Fail PA, George JD, Grizzle TB, Heindel J, Chapin RE. Final report on the reproductive toxicity of boric acid in CD-1-Swiss mice. National Toxicology Program, National Institute of Environmental Health Sciences, April 13, 1990. Research Triangle Park, NC: NIEHS, 1990. (NTIS PB90253808.)

7 Fail PA, George JD, Seely JC, Grizzle TB, Heindel JJ. Reproductive toxicity of boric acid in Swiss (CD-1) mice: assessment using the continuous breeding protocol. Fundam Appl Toxicol 1991;17:225-39.

8 Treinen KA, Chapin RE. Development of testicular lesion in F344 rats after treatment with boric acid. Toxicol Appl Pharmacol 1991;107:325-35.

$9 \mathrm{Ku}$ WW, Chapin RE, Moseman RF, Brink RE, Pierce $\mathrm{KD}$, Adams KY. Tissue disposition of boron in male Fischer rats. Toxicol Appl Pharmacol 1991;111:145-51.

10 Lee IP, Sherins RJ, Dixon RL. Evidence for induction of germinal aplasia in male rats by environmental exposure
to boron. Toxicol Appl Pharmacol 1978;45:577-90.

11 International Labour Organisation. Occupational exposure limits for airborne toxic substances; a tabular compilation of values from selected countries. Geneva: ILO, 1977. (Occupational Safety and Health Series No 37).

12 Wong O, Utidjian HMD, Karten VS. Retrospective evaluation of reproductive performance of workers exposed to ethylene dibromide (EDB). $\mathcal{F}$ Occup Med 1979;21: 98-102.

13 Wong O, Morgan RW, Whorton MD. An epidemiologic surveillance program for evaluating occupational reproductive hazards. Am F Ind Med 1985;7:295-306.

14 Joffé M, Villar L, Li Z, Plowman R, Vessey M. Long-term recall of time-to-pregnancy. Fertil Steril 1993;60:99-104.

15 Mosher WD, Pratt WF, eds. US Department of Health and Human Services, Contraceptive use in the United and Human Services, Contraceptive use in the United
States, 1973-1988. Division of Vital Statistics. States, 1973-1988. Division of Vital Statistics.
Washington: USDHHS, 1990. National Center for Washington: USDHHS,

16 US Department of Health, Education and Welfare. Characteristics of Births. United States, 1973-1975. Hyattsville, MD: DHEW, 1978. (DHEW/78-1908/ 11-12.)

17 Potashnik G, Goldsmith J, Insler V. Dibromochloropropane-induced reduction of the sex-ratio in man. Andrologia 1984;16:213-8.

18 Bailer JC, Ederer F. Significance factors for the ratio of a Poisson variable to its expectation. Biometrics 1964;20: 639-43.

$19 \mathrm{Hu}$ X, Eisen EA, Woskie SR, Smith RG. Dose related acute irritant symptom responses to occupational sodium borate dusts. Br 7 Ind Med 1992;49:706-13.

20 Whorton MD, Milby TH, Krauss RM, Stubbs HA. Testicular function in DBCP exposed pesticide workers. f Occup Med 1979;21:161-6.

21 Amato I. Are chemists girl crazy. Science 1992;257:158-9.

22 Levine RJ, Symons MJ, Balogh SA, Arndt DM, Kaswandik NT, Gentile JW. A method of monitoring the fertility of workers. I. Method and pilot studies. f Occup Med 1980;22:781-91. 